\title{
Enhanced solubility and functionality of valrubicin (AD-32) against cancer cells upon encapsulation into biocompatible nanoparticles
}

This article was published in the following Dove Press journal:

International Journal of Nanomedicine

21 February 2012

Number of times this article has been viewed

\author{
Nirupama Sabnis' \\ Maya Nair \\ Mervyn Israel ${ }^{2}$ \\ Walter J McConathy ${ }^{3}$ \\ Andras G Lacko' \\ 'University of North Texas Health \\ Science Center, Fort Worth, TX, \\ ${ }^{2}$ University of Tennessee Health \\ Science Center, Memphis, TN \\ ${ }^{3}$ Texas Tech University Health \\ Sciences Center-Permian Basin, \\ Odessa, TX, USA
}

\begin{abstract}
Among numerous drug-delivery approaches, reconstituted high-density lipoprotein (rHDL) nanocarriers have proven particularly applicable for delivering highly hydrophobic drugs. In this study, we have investigated the enhancement of the therapeutic impact of valrubicin (AD-32), an antineoplastic agent that has been limited to intravesicular application against bladder cancer, despite the encouraging original preclinical data. Earlier studies validated the superior therapeutic efficacy of AD-32 over doxorubicin. In the present study, rHDL/AD-32 nanoparticles were formulated and characterized with regard to encapsulation efficiency, physicochemical properties, selective toxicity, and receptor-mediated uptake. The half maximal inhibitory concentration values $\left(\mathrm{IC}_{50}\right)$ for $\mathrm{rHDL} / \mathrm{AD}-32$ nanoparticles were 1.8 and 2.6 times lower than the free $\mathrm{AD}-32$ for prostate (PC-3) and ovarian (SKOV-3) cancer cell lines, respectively, whereas nonmalignant cell lines demonstrated 5 and 1.48 times higher $\mathrm{IC}_{50}$ doses with $\mathrm{rHDL} / \mathrm{AD}-32$ formulations. The data obtained demonstrated effective receptor-mediated uptake of AD-32 from the rHDL nanocarriers by PC-3 and SKOV-3 cancer cells via a targeted drug-delivery process. The rHDL/AD-32 formulation was stable for 6 months when stored at $4^{\circ} \mathrm{C}$ or at $-20^{\circ} \mathrm{C}$, as $92 \%$ of the $\mathrm{AD}-32$ was retained in the nanoparticles. The findings from this study show that the rHDL/AD-32 formulation can overcome the solubility barriers of AD-32 and thus serve as an effective systemically administered chemotherapeutic agent.
\end{abstract}

Keywords: AD-32, rHDL, nanoparticles, targeted drug delivery, selective drug delivery

\section{Introduction}

Drug delivery via nanotechnology is one of the vanguards of the rapidly expanding field of cancer therapeutics. ${ }^{1-3}$ A variety of submicron drug carrier systems have been developed recently to improve the delivery and retention of pharmaceuticals by malignant cells and tumors. ${ }^{4,5}$ Lipid-containing nanoparticles (LNs) represent an alternative delivery system to traditional carriers, such as emulsions, liposomes, and polymeric nanoparticles, especially for the delivery of lipophilic drugs. ${ }^{5,6}$ While LNs have several advantages over other formulations, they also have serious limitations such as nonselective toxicity, instability, and limited drug payload. ${ }^{6-8}$ Encapsulation of drugs within the reconstituted high-density lipoprotein (rHDL) nanocarriers has shown great potential for cancer chemotherapy by minimizing limitations encountered with conventional formulations, including LNs and liposomes. ${ }^{9-11}$ The rHDL nanoparticles have been identified as an effective drug-delivery system for highly lipophilic drugs ${ }^{11-13}$ and for small interfering RNA (siRNA). ${ }^{14}$ The proof of concept studies using rHDL nanoparticles loaded with paclitaxel, dilauryl-fluorescein, and siRNA have shown that
Correspondence: Andras G Lacko Department of Molecular Biology/ Immunology, University of North Texas Health Science Center, 3500 Camp Bowie Blvd, Fort Worth, TX 76107 USA $\mathrm{Tel}+\mathrm{I} 8177352132$

Fax +18177352118

Email andras.lacko@unthsc.edu 
the delivery of the drug to cancer cells and tumors occurs via a targeted, receptor-mediated mechanism involving the scavenger receptor class B type 1 (SR-B1). ${ }^{13-16}$

The current study was undertaken to evaluate the in vitro therapeutic efficacy of valrubicin [AD-32 ( $N$-trifluoroacetyladriamycin-14-valerate)], a derivative of doxorubicin, which was originally developed as a cancer therapeutic agent, ${ }^{17-19}$ leading to its restricted approval for treating Bacillus Calmette-Guerin (BCG)-resistant bladder cancers in $1998 .{ }^{20,21}$ Even though AD-32 has been found to be much less toxic to normal tissues ${ }^{16,22}$ than doxorubicin during preclinical studies, its therapeutic application has been confined to nonsystemic administration due to its poor water solubility. This restriction remains in place except for recent attempts to extend the application of $\mathrm{AD}-32$ to treat skin cancer and psoriasis via topical formulations. ${ }^{23,24}$ The highly hydrophobic nature of AD-32 and its proven antineoplastic properties make it a promising candidate to serve as an effective chemotherapeutic agent when used in conjunction with the rHDL nanoparticles as delivery vehicles. In our present work, we formulated AD-32 with rHDL nanocarriers using the cholate dialysis technique. ${ }^{13}$ These particles were then characterized for their encapsulation efficiency and physicochemical properties. The rHDL/AD-32 nanocarriers were also evaluated for their effect on cell viability in malignant prostate (PC-3) and ovarian (SKOV-3) cell lines, and nonmalignant prostate (PZ-HPV) and ovarian (HiO 180) epithelial cells. Drug uptake through the SR-B1 receptors, the in vitro release profile, and the stability of formulations were also studied in detail.

\section{Materials}

Sodium cholate, egg yolk phosphatidyl choline (PC), free cholesterol, cholesteryl oleate, potassium bromide ( $\mathrm{KBr})$, isopropyl thiogalactoside (IPTG), dimethyl sulfoxide (DMSO), Triton X-100, and thrombin cleavage kit were purchased from Sigma-Aldrich Corporation, St Louis, MO. NZYCM was obtained from Teknova, Hollister, CA. Bacterial protein extraction reagent and bicinchoninic acid (BCA) protein assay kits were purchased from Thermo Scientific, Rockford, IL. A histidine-trap (His-Trap) affinity column was obtained from QIAGEN, Valencia, CA. Cholesterol and phospholipid estimation kits were obtained from Wako Pure Chemical Industries Ltd, Richmond, VA. Roswell Park Memorial Institute 1640 media, keratinocyte media and fetal bovine serum were obtained from Gibco, Invitrogen, Carlsbad, CA. AD-32 was provided by Dr Mervyn Israel, University of Tennessee Health Science Center, Memphis, TN. Low protein binding durapore membrane syringe filters were purchased from Millipore Ltd, Billerica, MA. Established cancer cell lines PC-3, SKOV-3, and PZ-HPV were obtained from American Type Culture Collection (ATCC), Manassas, VA. The ovarian epithelium cell line HiO 180 was provided by Dr Anil K Sood of MD Anderson Cancer Center, Houston, TX. The cell counting kit (CCK-8) was purchased from Dojindo Laboratories, Tabaru, Japan.

\section{Methods}

\section{Preparation of the AD-32 containing nanoparticles}

Isolation and purification of recombinant apoA-I

These were performed essentially as described by Ryan et al. ${ }^{25}$ Briefly, BL21(DE3)pLysS cells bearing the pNFXex plasmid were cultured in $500 \mathrm{~mL}$ NZYCM media $\left(+50 \mu \mathrm{g} / \mathrm{mL}\right.$ ampicillin) at $37^{\circ} \mathrm{C}$. When the culture optical density reached 0.6 at $600 \mathrm{~nm}$, apoA-I synthesis was induced by the addition of IPTG to a final concentration of $0.5 \mathrm{mM}$. After 3 hours, the bacteria were pelleted by centrifugation and disrupted by lysis buffer (bacterial protein extraction reagent). The cell lysate was centrifuged at 20,000 $\mathrm{g}$ for 30 minutes at $4^{\circ} \mathrm{C}$. The supernatant fraction was mixed with an equal volume of phosphate-buffered saline (PBS) containing $6 \mathrm{M}$ guanidine hydrochloric acid $(\mathrm{HCl})$, applied to a $5 \mathrm{~mL}$ bed volume His-Trap affinity column, and purified as per manufacturer's instructions. The N-terminal His-Tag extension was removed using a thrombin CleanCleave kit (Sigma-Aldrich). The isolated apo A-I was then dialyzed against tris(hydroxymethyl)aminomethane (Tris)-buffered saline containing $1 \mathrm{mM}$ benzamidine for 16 hours at $4^{\circ} \mathrm{C}$. The dialyzed sample was filter-sterilized $(0.2 \mu \mathrm{m})$ and stored at $4^{\circ} \mathrm{C}$ until use.

\section{Preparation of rHDL/AD-32 complexes with apo A-I}

This was accomplished by a procedure developed earlier in our laboratory. ${ }^{10,13}$ Briefly, a mixture of egg yolk $\mathrm{PC}$ in $\mathrm{CHCl}_{3}$ with free cholesterol (FC), and cholesteryl oleate (CE), was prepared with a molar ratio of ApoA1:FC:CE:PC = 1:5:1.3:1.15 M. The lipid mixture (PC, FC, and $\mathrm{CE}$ ) and the drug (AD-32) were dried under $\mathrm{N}_{2}$ to a thin film and dispersed in $60 \mu \mathrm{L}$ DMSO. To this mixture, apo A-I ( $5 \mathrm{mg}$ ) and $140 \mu \mathrm{L}$ sodium cholate (from a stock of $100 \mathrm{mM}$ ) were added and the volume was made up to $2 \mathrm{~mL}$ with Tris-ethylenediaminetetraacetic acid (EDTA) buffer (10 mM Tris, $0.1 \mathrm{M} \mathrm{KCl,} 1 \mathrm{mM}$ EDTA $\mathrm{pH}$ 8.0). (Final $\mathrm{PC}$ to cholate molar ratio was maintained at $\sim 1: 1.6)$. The lipid/protein/cholate mixture was then incubated 
for 12 hours at $4^{\circ} \mathrm{C}$, followed by dialysis against $2 \mathrm{~L}$ of PBS, for 48 hours, with three buffer changes in the first 12 hours. The preparations were then centrifuged at $1000 \mathrm{rpm}$ for 2 minutes and sterilized using a $0.2 \mu \mathrm{m}$ syringe filter. The preparations were kept in the dark at $4^{\circ} \mathrm{C}$ until used.

\section{Characterization of rHDL/AD-32 nanoparticles}

\section{Chemical composition}

Cholesterol and phospholipids were determined by respective enzymatic reagent kits (cholesterol E and phospholipid C), using microtiter plate assays as per manufacturer's suggestions. Protein determinations were carried out using a BCA protein assay kit. The percentage drug incorporation was determined by fluorescence spectroscopic measurements, in a Cary Eclipse Spectrofluorometer (Varian Inc, Mulgrave, Australia).

\section{Determination of entrapment efficiency of AD-32 in the rHDL/AD-32 nanoparticles}

The drug entrapment efficiency (DEE) was determined by measuring the amount of AD-32 in the formulations before the cholate dialysis step mentioned earlier (initial drug) and after filtration (final drug incorporated). DEE was calculated using the following formula: $\mathrm{DEE}=\{$ Drug concentration after dialysis/Drug concentration before dialysis $\} \times 100$.

\section{Drug-loading studies with rHDL/AD-32 nanoparticles}

rHDL/AD-32 particles were prepared using increasing initial concentrations of AD-32 while keeping all other ingredients constant. Final drug concentration and DEE were calculated as described above.

\section{Ultracentrifugation}

$\mathrm{KBr}, 1.2 \mathrm{~g} / \mathrm{mL}$, was added to $3 \mathrm{~mL}$ of sample. The sample was layered with $\mathrm{KBr}$ solutions with the corresponding designated densities ( $1 \mathrm{~mL}, 1.22 \mathrm{~g} / \mathrm{mL} ; 4 \mathrm{~mL}, 1.063 \mathrm{~g} / \mathrm{mL}$; and $3 \mathrm{~mL}, 1.019 \mathrm{~g} / \mathrm{mL}$ ) and centrifuged in an Optima LE 80K ultracentrifuge (Beckman Coulter, Brea, CA) for 36 hours at $39,000 \mathrm{rpm}$ at $4^{\circ} \mathrm{C}$ using a swinging bucket rotor ( $\mathrm{SW}$ $40)$ in a Beckman. ${ }^{26}$ Fractions $(1 \mathrm{~mL})$ were collected corresponding to very low-density lipoprotein (fraction 1-2, $P=<1.007 \mathrm{~g} / \mathrm{mL}$ ); intermediate density lipoprotein (fraction $3, P=1.007-1.02 \mathrm{~g} / \mathrm{mL}$ ); low-density lipoprotein (fractions 4-6, $P=1.020-1.060 \mathrm{~g} / \mathrm{mL}$ ); high-density lipoprotein (HDL) (fractions 7-8, $P=1.060-1.15 \mathrm{~g} / \mathrm{mL}$ ): $\mathrm{HDL}_{3}$ (fractions 9-10, $P=1.15-1.235 \mathrm{~g} / \mathrm{mL}$ ) and lipoprotein deficient serum (fractions $11-13, P>1.235 \mathrm{~g} / \mathrm{mL}$ ), and subsequently analyzed for protein, phospholipid, and cholesterol.

\section{Estimation of the size and morphology of rHDL/AD-32 nanoparticles \\ Dynamic light scattering (DLS)}

Particle size analysis of the AD-32-loaded rHDL nanoparticles was carried out using a Nanotrac system (Microtrac Inc, Montgomeryville, PA) as per manufacturer's instructions. The nanoparticles were dispersed in aqueous buffer using an ultrasonic waterbath (Fisher Scientific, Pittsburgh, PA) for 2 minutes and then measured for particle size.

The results were reported as the average of three independent runs with duplicate observations in each run.

\section{Atomic force microscopy (AFM)}

The rHDL-AD-32 formulation was dialyzed at $4^{\circ} \mathrm{C}$ for 12-18 hours against sterile distilled and deionized water to remove the salts from the solution. It was further diluted 1:5 with sterile distilled water. Ten microliters of the sample was then placed on the microscope slide and was allowed to air dry. Sample was then processed with AFM on an NTEGRA Prima scanning probe microscope (NT-MDT, Santa Clara, CA). Closed-loop feedback semicontact mode was used at a rate of $0.6 \mathrm{~Hz}$. Scanning started from the $50 \mu \mathrm{m}$ area, going down to $5 \mu \mathrm{m}$. The images obtained were analyzed with NTMDT image analysis software (v 2.2). At least 25 individual particles were measured from three different positions and the average diameter was reported.

\section{Transmission electron microscopy (TEM)}

Following dialysis in a volatile buffer $(0.125 \mathrm{M}$ ammonium acetate, $2.6 \mathrm{mM}$ ammonium carbonate, $0.26 \mathrm{mM}$ EDTA, $\mathrm{pH}$ 7.4), the isolated rHDL samples were negatively stained with $2 \%$ sodium phosphotungstate, $\mathrm{pH} 7.2$ and placed on Formvar/Carbon-coated 200 mesh nickel grid support films (Ted Pella Inc, Redding, CA) as previously described. ${ }^{27}$ The particles were visualized using a magnification of 50,000 on a Zeiss 910 transmission electron microscope (Carl Zeiss, Thornwood, NY). The pictures were enhanced and the particle diameter determined with Adobe ImageReady CS2 software (Adobe Systems, San Jose, CA).

\section{Effect of free and rHDL encapsulated $A D-32$ on cell viability}

Culturing of the malignant prostate cancer cell line (PC-3), malignant ovarian cancer cell line (SKOV-3) and 
nonmalignant ovarian epithelial cell line (HiO180) were carried out according to procedures and culturing conditions provided by the ATCC. ${ }^{28,29}$ Briefly, the cells were cultured in Roswell Park Memorial Institute 1640 containing $2.05 \mathrm{mM}$ L-glutamine and 10\% fetal bovine serum. A nonmalignant prostate epithelial cell line (PZ-HPV) was grown in keratinocyte medium supplemented with $10 \%$ fetal bovine serum medium containing human recombinant epidermal growth factor and bovine pituitary extract (both from Invitrogen) as per manufacturer's instructions. All the cells were grown in $75 \mathrm{~cm}^{2}$ flasks and incubated at $37^{\circ} \mathrm{C}$ and $5 \% \mathrm{CO}_{2}$. Cells were passaged using $0.25 \%$ trypsin to release the cells from the flasks, once $80 \%-90 \%$ confluency was reached.

\section{Preparation of drug formulations}

A stock solution $(50 \mathrm{mg} / \mathrm{mL})$ of AD-32 in DMSO was prepared by emulsifying the drug in $50 \%$ sterile bovine serum albumin (BSA)/PBS by stirring. Samples for the characterization studies were prepared by diluting the stock with PBS to achieve equivalent AD-32 molar concentration to that contained by the respective $\mathrm{HDL} / \mathrm{AD}-32$ nanoparticle samples. (The unencapsulated AD-32 suspension in BSA is referred to as "free drug.")

\section{Determination of $\mathrm{IC}_{50}$ doses}

The effect of AD-32 in free drug and rHDL encapsulated particles was studied using CCK-8 kit (Dojindo Molecular Technologies, Tabaru, Japan). ${ }^{30}$ Briefly, the PC-3, SKOV-3, PZ-HPV, and HiO180 were grown according to procedures and culturing conditions provided by the ATCC in their respective media as stated earlier in $75 \mathrm{~cm}^{2}$ flasks and incubated at $37^{\circ} \mathrm{C}$ and $5 \% \mathrm{CO}_{2}{ }^{28,29}$ Cells were passaged using $0.25 \%$ trypsin to release the cells from the flasks, once $80 \%-90 \%$ confluency was reached. Cells were counted using hemocytometer and 5000 cells were seeded per well into 96 -well microtiter plates and incubated at $37^{\circ} \mathrm{C}$ in $5 \%$ $\mathrm{CO}_{2}$ for 24 hours to allow the cells to attach to the plates. The free drug and the rHDL/AD-32 nanoparticles were diluted in serum-free medium to yield stock solutions of equivalent molar concentrations. Subsequently, aliquots of the stock solutions were added to microtiter plate wells to achieve the selected concentration range for the cell viability tests. Controls included cells with media (without rHDL/drug), cells with empty rHDL particles, and media without cells with same rHDL/drug and free drug of each concentration used. Cells were incubated at $37^{\circ} \mathrm{C}$ in $5 \% \mathrm{CO}_{2}$ for 24 hours. After incubation, $10 \mu \mathrm{L}$ of highly water-soluble tetrazolium salt, WST-8 [2-(2-methoxy-4-nitrophenyl)-3-(4-nitrophenyl)-5-
(2,4-disulfophenyl)-2H-tetrazolium, monosodium salt] stock solution (Dojindo) was added to each well. After 3 hours of incubation at $37^{\circ} \mathrm{C}$, the absorbance at $450 \mathrm{~nm}$ was measured using a Bio-Rad 3550 microplate reader (Bio-Rad Laboratories, Hercules, CA). Each concentration was studied with six replicates.

\section{Monitoring the uptake of the drug payload from the rHDL/AD-32 complex}

Cells were plated in 24-well plates $(100,000$ cells/well) in their respective media. On the following day, the monolayers were washed with $\mathrm{PBS}, \mathrm{pH} 7.4$, and then incubated at $37^{\circ} \mathrm{C}$ with serum-free medium for 90 minutes. Cells were washed with PBS and incubated with a single concentration of the rHDL/AD-32 complex plus increasing amounts of HDL $(0-120 \mu \mathrm{g})$ in serum-free medium for 90 minutes. The preparation was washed once with $1 \times \mathrm{PBS}$, pH 3.0, and subsequently with $1 \times \mathrm{PBS}, \mathrm{pH}$ 7.4. The cells were then lysed with lysis buffer (50 mm Tris- $\mathrm{HCl}$ [pH 8.0], $150 \mathrm{mM} \mathrm{NaCl}$, $0.02 \%$ sodium azide, $100 \mu \mathrm{g} / \mathrm{mL}$ phenylmethanesulfonylfluoride, $1 \mu \mathrm{g} / \mathrm{mL}$ aprotinin, and $1 \%$ Triton $\mathrm{X}-100)$. The lysate was centrifuged at $10,000 \mathrm{rpm}$ for 5 minutes. The protein and AD-32 content of the lysate was determined by BCA assays and spectrophotometric measurements respectively as described above.

\section{In vitro release studies}

These were performed using a dynamic dialysis technique, ${ }^{31-33}$ modified to maintain a sink condition for improved reproducibility. A $2 \mathrm{~mL}$ sample of AD-32-rHDL preparation was transferred to a dialysis bag with molecular weight cut off of 6000-8000 MW and placed into the preheated dissolution medium at $37^{\circ} \mathrm{C}$ containing $100 \mathrm{~mL}$ of $\mathrm{PBS}$ at $\mathrm{pH} 7.4$. The suspension was stirred at $37^{\circ} \mathrm{C} \pm 0.5^{\circ} \mathrm{C}$ using a gyratory shaker at $50 \mathrm{rpm}$. Five hundred microliters of the sample was withdrawn at fixed time intervals and replaced with the same volume of fresh buffer. Samples were scanned using Cary Winuv scan software (v 3.00) in a Cary Varian UV-visible spectrophotometer (Agilent Technologies, Santa Clara, CA). Free AD-32 in pH 7.4 PBS was used as a control. All the operations were carried out in triplicate. The amount of AD-32 released from the dialysis bags were measured using a standard graph with a known concentration range of AD-32 versus absorbance at $490 \mathrm{~nm}$.

\section{Stability studies}

These were performed at $4^{\circ} \mathrm{C}$ and $-20^{\circ} \mathrm{C}$. The particles were stored at $4^{\circ} \mathrm{C}$ and $100 \mu \mathrm{L}$ aliquots were removed at desig- 
nated time periods. The samples were dialyzed using dialysis tubing with an $8000 \mathrm{MW}$ cut off at $4^{\circ} \mathrm{C}$ for 18 hours. The $\mathrm{AD}-32$ content and particle size before and after dialysis were determined spectrophotometrically and by DLS methods respectively as described above.

\section{Stability to lyophilization}

rHDL/AD-32 particles were dialyzed against 0.1 M PBS. The nanoparticles were freeze dried at $-46^{\circ} \mathrm{C} / 0.5 \mathrm{Mbar}$ in a Labconco freeze drier (Labconco Corp, Kansas City, MO) until they were completely dry, producing a powder. The freeze-dried preparations were stored at $-20^{\circ} \mathrm{C}$ for 24 hours and then reconstituted in $1 \times$ PBS. The AD-32 content and particle size before and after dialysis were determined spectrophotometrically and by dynamic light scattering methods respectively as described above.

\section{Results}

\section{Characterization of rHDL/AD-32 nanoparticles}

Assembly of the AD-32-containing nanoparticles was achieved by the cholate dialysis procedure, developed earlier in our laboratory. ${ }^{13,15}$ As shown in Table 1, the predominant component of the rHDL/AD-32 nanoparticles was phospholipid $(62.0 \%)$, followed by protein $(28.8 \%)$, cholesterol $(0.96 \%)$ and AD-32 (8.3\%). The phospholipid to protein ratio was 2.15:1 for the drug-loaded nanoparticles as compared with 1.96:1 for the empty particles (without drug). The entrapment efficiency of AD-32 in the rHDL nanoparticles was assessed by preparing particles with an increase in the initial concentration of AD-32 while keeping the amount and proportions of all the other components constant. As indicated in Figure 1, the entrapment efficiency of AD-32 decreased from $96 \%$ to $32.7 \%$ with an increase in the initial concentration of AD-32 from $0.5 \mathrm{mg} / \mathrm{mL}$ to $3 \mathrm{mg} / \mathrm{mL}$. The highest amount of drug was incorporated at the initial concentration of $2 \mathrm{mg} / \mathrm{mL}$.

The size of the rHDL/AD-32 nanoparticles was determined using three methods: DLS, TEM, and AFM. The DLS data in Figure 2A depict a relatively narrow size distribution ranging from 29 to $120 \mathrm{~nm}$ with the mean particle size being $43.7 \mathrm{~nm}$. The images obtained by AFM

Table I Chemical composition of rHDL/AD-32 particles

\begin{tabular}{lllll}
\hline Type & \multicolumn{4}{l}{ rHDL components $\mathbf{m g} / \mathbf{m L}(\%)$} \\
\cline { 2 - 5 } of particles & Protein & Phospholipid & Cholesterol & AD-32 \\
\hline rHDL/AD-32 & $2.04(28.8)$ & $4.39(6 I .9)$ & $0.07(0.96)$ & $0.59(8.3 \mathrm{I})$ \\
Empty rHDL & $2.34(33.4)$ & $4.58(65.3)$ & $0.09(1.3 \mathrm{I})$ & 0 \\
\hline
\end{tabular}

Abbreviations: $A D-32$, valrubicin; $r H D L$, reconstituted high-density lipoprotein.

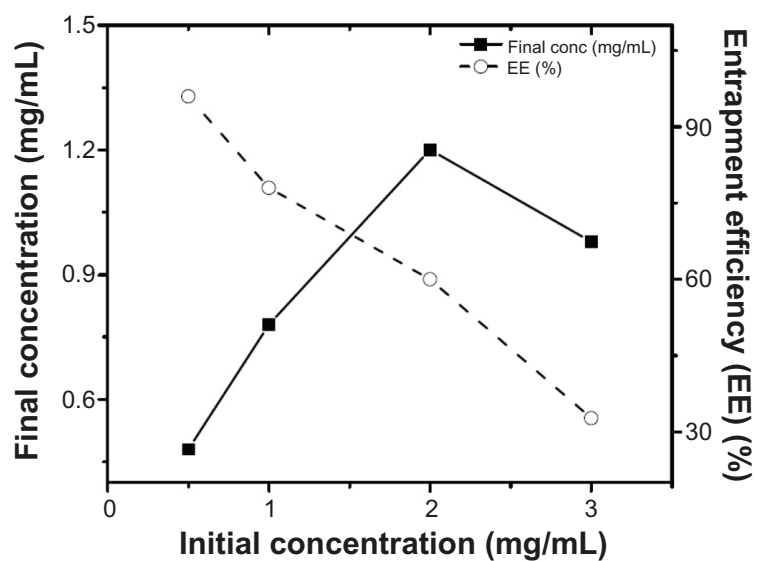

Figure I Loading efficiency of AD-32 into rHDL nanoparticles via the cholate dialysis process (see methods for details).

Abbreviations: AD-32, valrubicin; rHDL, reconstituted high-density lipoprotein.

(Figure 2B) and TEM (Figure 2C) indicated the presence of spherical particles with a diameter ranging from 15 to $25 \mathrm{~nm}$ and mean particle size of 18 and $20 \mathrm{~nm}$, respectively. The data from DLS show larger diameter particles (compared with the data from TEM and AFM) as it has during our previous studies with other drug-containing nanoparticles (unpublished data). The buoyant density pattern of the AD-32 containing rHDL preparation is shown in Figure 3 as the distribution of fluorescence in a density gradient. The centrifugation pattern developed for the rHDL/AD-32 particles shows a peak in fraction \#8, coinciding with the position of circulating human HDL.

\section{Determination of $\mathrm{IC}_{50}$}

Cell viability assays (CCK-8) were performed using free AD-32, AD-32-loaded rHDL nanoparticles, and blank (empty) rHDL nanoparticles. Untreated cells and equivalent formulations without cells served as controls. The data for free AD-32 and AD-32 enclosed in rHDL nanoparticles depicted as the drug concentration required to inhibit cell growth by $50 \%\left(\mathrm{IC}_{50}\right)$, is shown in Table 2 . The $\mathrm{IC}_{50}$ for the AD-32-loaded rHDL nanoparticles was found to be greater than $48 \mu \mathrm{M}$ for both nonmalignant cell lines while the $\mathrm{IC}_{50}$ values for the free AD-32 were substantially lower $(9.5 \mu \mathrm{M}$ and $32.5 \mu \mathrm{M}$, respectively). These data indicate that the encapsulation in the rHDL nanoparticles protects normal (nonmalignant cells) from the impact of cytotoxic drugs. The $\mathrm{IC}_{50}$ values for the rHDL-enclosed and free $\mathrm{AD}-32$ samples for the PC-3 cells were 8.1 and $19.3 \mu \mathrm{M}$, respectively. A similar trend was observed for the SKOV-3 cells, where the $\mathrm{IC}_{50}$ for rHDL loaded AD-32 particles and free drug were 11.9 and $21.5 \mu \mathrm{M}$, respectively. These data show that 
A

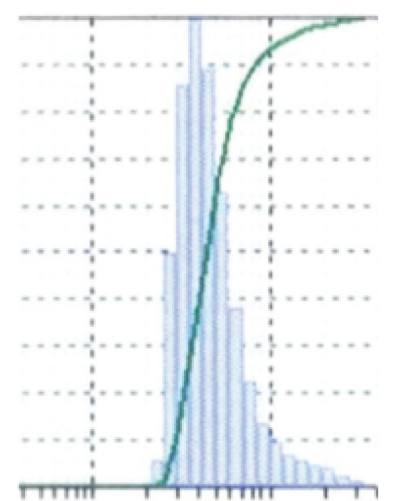

10
B

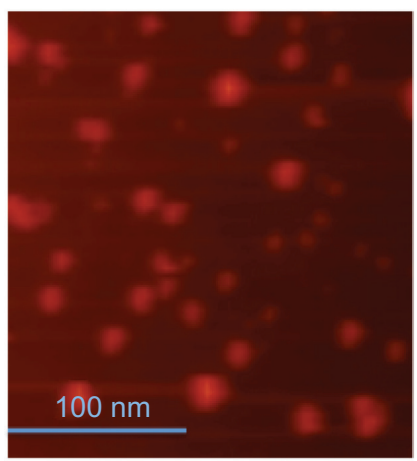

C

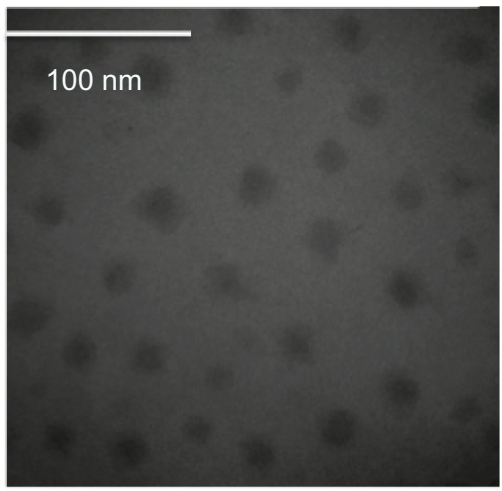

\section{Particle diameter (nm)}

Figure 2 Estimation of the diameter of the AD-32 containing rHDL nanoparticles by (A) dynamic light scattering, (B) atomic force microscopy, and (C) transmission electron microscopy.

Abbreviations: AD-32, valrubicin; rHDL, reconstituted high-density lipoprotein.

the encapsulation in the rHDL nanoparticles enhances the cytotoxic potential of AD-32 against malignant cells as we have shown earlier for paclitaxel. ${ }^{13}$

\section{Uptake of AD-32 from rHDL particles by malignant and nonmalignant cells}

Uptake of AD-32 by the PZ-HPV, PC-3 (prostate), HiO180, and SKOV-3 (ovarian) cell lines was assessed in the presence and absence of increasing amounts of human HDL (a competitor for the SR-B1 receptor). ${ }^{10,11,15}$ As shown in Figure 4, there was a substantial decrease in the uptake of AD-32 from the AD-32 containing rHDL nanoparticles by the malignant cells (PC-3 and SKOV-3), in response to the progressively increasing HDL concentrations in the incubation mix. The nonmalignant cells (PZ-HPV and HiO180), however, showed a much more limited response to increasing HDL, consistent with their lower expression of the SR-B1 receptor. ${ }^{10-12,14,15 .}$

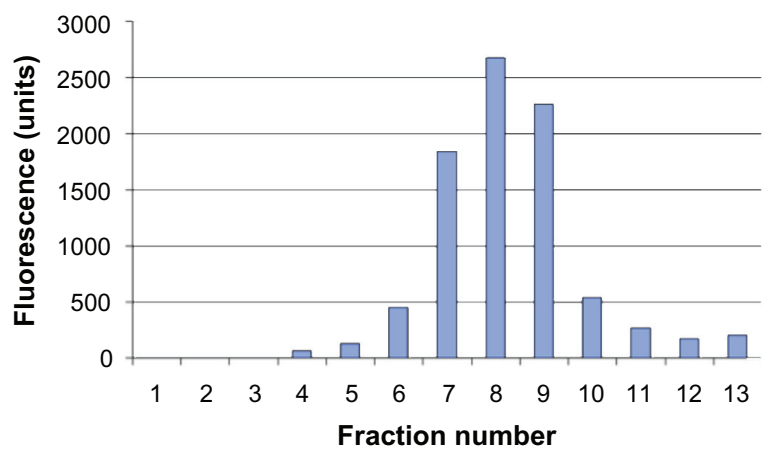

Figure 3 Distribution of the AD-32 containing rHDL nanoparticles subsequent to preparative ultracentrifugation (see text for experimental details).

Abbreviations: AD-32, valrubicin; rHDL, reconstituted high-density lipoprotein.

\section{Stability studies of AD-32 loaded rHDL nanoparticles}

As shown in Table 3, almost $90 \%$ of the AD-32 content of the rHDL nanoparticles was retained during 6 months storage at $4^{\circ} \mathrm{C}$. Ninety-two percent of the original AD-32 was retained within the rHDL particles following 6 months storage at $-20^{\circ} \mathrm{C}$. Lyophilization was found to be the best approach for sustained storage for the drug-containing $\mathrm{rHDL}$ nanoparticles. The mean diameter of the stored particles was found to be very close to that of the freshly prepared particles (Figure 2 and Table 3 ) indicating minimum aggregation upon rehydration from the powdered form.

\section{In vitro release profile of AD-32-loaded rHDL nanoparticles}

In vitro release studies were carried out by dynamic dialysis technique in a dialysis bag incubated at $37^{\circ} \mathrm{C}$ in PBS. About $80 \%$ of the integrity of rHDL/AD-32 nanoparticles was

Table 2 Cytotoxicity of AD-32, delivered by rHDL nanocarriers versus the free drug against malignant and normal cells

\begin{tabular}{lll}
\hline Cell lines used & $\begin{array}{l}\mathrm{IC}_{50} \text { for free } \\
\text { AD-32 }(\mu \mathrm{M})\end{array}$ & $\begin{array}{l}\mathrm{IC}_{50} \text { for } \mathrm{rHDL} \\
\mathbf{A D}-32(\mu \mathrm{M})\end{array}$ \\
\hline $\begin{array}{l}\text { Nonmalignant } \\
\text { PZ-HPV }\end{array}$ & 9.5 & $>48$ \\
HiOI80 & 32.5 & $>48$ \\
Malignant & & \\
PC-3 & 19.3 & 8.1 \\
SKOV-3 & 21.5 & 11.9 \\
\hline
\end{tabular}

Note: $48 \mu \mathrm{M}$ AD-32 was highest dose tested.

Abbreviations: PZ-HPV, nonmalignant prostate epithelial cell line; PC-3, prostate cancer cell line; HiOI80, nonmalignant ovarian epithelial cell line; SKOV-3, ovarian cancer cell line; rHDL, reconstituted high-density lipoprotein. 

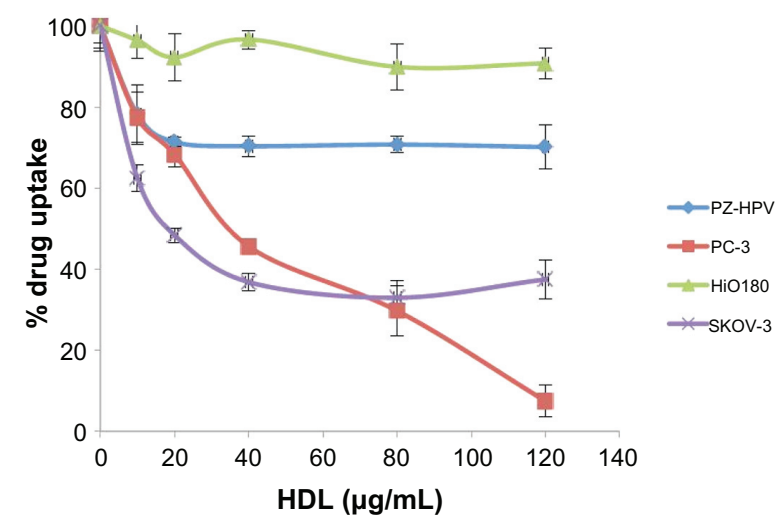

Figure 4 Comparative drug uptake studies from rHDL/AD-32 nanoparticles with malignant and non-malignant ovarian and prostate cell lines.

Abbreviations: AD-32, valrubicin; rHDL, reconstituted high-density lipoprotein; PZ-HPV, nonmalignant prostate epithelial cell line; PC-3, prostate cancer cell line; $\mathrm{HiO}$ 180, nonmalignant ovarian epithelial cell line; SKOV-3, ovarian cancer cell line; $\mathrm{HDL}$, high-density lipoprotein.

preserved up to 72 hours under these conditions. However, nearly $70 \%$ of the free drug was released within 8 hours and more than $90 \%$ of the drug was released after about 20 hours under the same dialysis conditions (Figure 5).

\section{Discussion}

AD-32 has been shown to have antineoplastic activity, low cardiotoxicity, and 24-fold higher lipophilicity than its parent compound, doxorubicin. ${ }^{17-20}$ While the chemotherapeutic potential of AD-32 was recognized earlier during preclinical studies, ${ }^{17,18}$ its application has so far been limited to vesicular treatment of bladder cancer, primarily due to its poor water solubility. ${ }^{21,34}$ Here, we report an attempt to overcome this solubility barrier by encapsulating the AD-32 in rHDL nanoparticles. ${ }^{11-16}$

The advantageous characteristics of HDL-based drug carriers include small size, selective delivery via receptor targeting, stability during storage, and high payload capacity. ${ }^{11-16}$ Encapsulation of lipophilic drugs within nanocarriers has shown great potential as an alternative or an adjunct to existing chemotherapy regimens. ${ }^{4,5}$ In addition, the selective targeting of malignant cells through receptor-mediated

Table 3 The stability of AD-32/rHDL particles at different storage conditions

\begin{tabular}{lll}
\hline Storage condition & \% drug recovery & $\begin{array}{l}\text { Mean diameter } \\
\text { (minimum-maximum) }\end{array}$ \\
\hline $4^{\circ} \mathrm{C}$ for 6 months & $89.9 \pm 3.4$ & $46.5(32-130) \mathrm{nm}$ \\
$-20^{\circ} \mathrm{C}$ for 6 months & $92.3 \pm 2.8$ & $48.3(28-120) \mathrm{nm}$ \\
Lyophilization & $94.6 \pm 4.1$ & $43.7(30-121) \mathrm{nm}$ \\
$\left(-46^{\circ} \mathrm{C} / 0.5\right.$ Mbar $)$ & & \\
\hline
\end{tabular}

Abbreviations: $A D-32$, valrubicin; rHDL, reconstituted high-density lipoprotein.

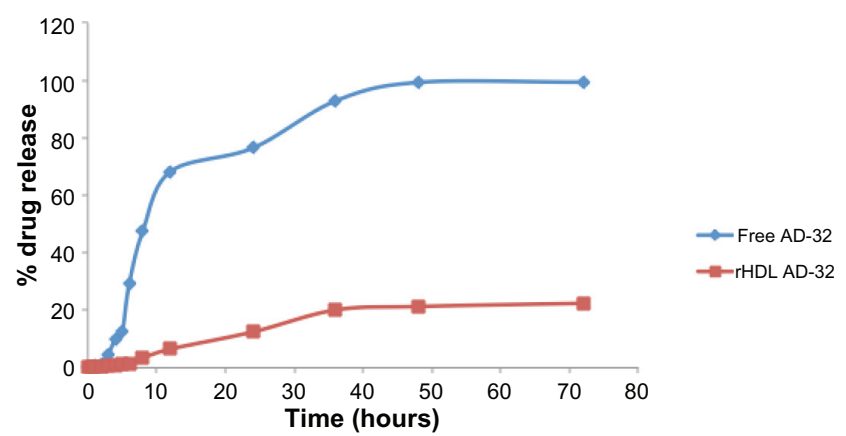

Figure 5 Release of AD-32 during dialysis when encapsulated in rHDL nanoparticles vs release of the free drug (see under Methods for experimental details). Abbreviations: AD-32, valrubicin; rHDL, reconstituted high-density lipoprotein.

uptake of anticancer drugg ${ }^{13,14}$ is a key concept in mediating or eliminating the side effects of conventional chemotherapy. The present study was undertaken to evaluate the potential of AD-32 as a chemotherapeutic agent upon encapsulation into biocompatible rHDL nanoparticles.

The rHDL/AD-32 particles were prepared by cholate dialysis, producing macromolecular structures that resembled circulating HDL with respect to physical and chemical characteristics. The rHDL/AD-32 nanoparticles, prepared by cholate dialysis, exhibited physico-chemical properties similar to that of native (circulating) human HDL10. ${ }^{16}$ Overall, these particles exhibited similar shape, size, and chemical composition to formulations of rHDL/dilauryl fluorescein and rHDL/paclitaxel particles, described earlier. ${ }^{13,15}$ The discrepancy in the size by DLS and other methods is likely to be due to the bias of the light scattering instrument toward larger particles. The key findings of this study are that AD-32 could be efficiently encapsulated into rHDL nanoparticles yielding a stable (nonleaking) preparation that efficiently delivers its payload to cancer cells. A major advantage of the rHDL drug-delivery system is that the particles are composed of naturally occurring biodegradable ingredients found in the vascular system. Consequently, they are not likely to elicit any immunological response in the host. Thus, it is anticipated that the rHDL nanoparticles have a relatively extended residence time in the circulation (similar to HDL) compared with most traditional drug-delivery vehicles, including liposomes. These physicochemical properties of rHDL/AD-32 emphasize its candidacy as an effective delivery model for anticancer agents and other systemically administered drugs.

Doxorubicin alone or in combination with other drugs has been reported to be effective against a wide range of cancers including prostate, ovarian, and breast carcinoma. ${ }^{35,36}$ Despite its reduced cardiotoxicity, $\mathrm{AD}-32$ has been mainly restricted to 
the treatment of bladder cancer. In order to evaluate the efficacy of AD-32 in the treatment of prostate and ovarian cancer, we have examined its effects on malignant and nonmalignant cells of prostatic and ovarian origin. Nonmalignant cells of both the PZ-HPV and HiO180 lines were more sensitive to the free AD-32 than to the rHDL-encapsulated drug preparation, suggesting better protection against cytotoxic effects of the encapsulated drugs provided by the rHDL carrier for normal cells and tissues. ${ }^{14}$ The cancer cells, however, exhibited increased sensitivity to the rHDL encapsulated drug formulation as compared with the cytotoxic effect of the free drug, probably due to the higher expression of the SR-B1 receptor in malignant cells. ${ }^{10-12,14,15}$ These observations are consistent with our earlier studies with other chemotherapeutic agents on malignant cancer cells. ${ }^{10-12,14,15}$ Additional studies were conducted to probe the delivery mechanism of AD-32 by evaluating the effect of added human HDL on the drug uptake by the malignant and nonmalignant cells. Earlier, we showed that the majority of the drug molecules are taken up from the rHDL nanoparticles by cancer cells via the SR-B1 receptor, whose normal function includes the extraction of cholesteryl esters from HDL. ${ }^{14,15}$ This receptor has been shown to be markedly overexpressed in malignant cells and tissues, apparently because of their need for excess cholesterol, due to their high proliferative rates. ${ }^{10-12,14,15}$ A progressive decrease in the AD-32 uptake from rHDL nanoparticles was observed when the cancer cells were pre-incubated with human HDL. These findings suggest that the added HDL competes with rHDL for the receptor sites and that the uptake of AD-32 by cancer cells from rHDL nanoparticles is also facilitated by HDL/ SR-B1 receptors. ${ }^{11,15}$ Previous studies have demonstrated that accumulation of the siRNA (delivered via the rHDL nanoparticles) was undetectable in nearly all normal tissues (except marginally in the liver) while it was substantial in tumor tissue, suggesting that selective drug delivery to tumors via rHDL is feasible. ${ }^{11,12,14}$ The selective tumor delivery concept would make the rHDL nanoparticles outstanding drug-delivery candidates for the purposes of reducing off-target effects and avoiding drug resistance during cancer chemotherapy.

The stability studies of rHDL/AD-32 particles under different conditions demonstrated the ease of storage of these particles for long-term use. In particular, the stability subsequent to lyophilization enhances the feasibility of the AD-32/rHDL drug-delivery system for clinical applications. Furthermore, in vitro drug-release studies carried out at physiological $\mathrm{pH}$ conditions emphasize nonleaky formulations that could sustain these drug-loaded particles longer in circulation.

\section{Conclusion}

In this study, we prepared AD-32 containing rHDL nanoparticles that exhibited up to $96 \%$ entrapment efficiency and formed smooth, spherical particles with mean diameter size of 15-20 nm. The formulation was stable and nonleaking under several storage conditions. The findings from cytotoxicity and drug-uptake studies on malignant and normal (prostate and ovarian) cell lines suggest for the first time that the chemotherapeutic efficacy of AD-32 upon encapsulation in biocompatible nanoparticles may be markedly enhanced by the reduction (or elimination) of harmful side effects, due to selective tumor delivery of the anticancer agent, thus making it a potential candidate for alternate or adjuvant chemotherapeutic regimens.

\section{Acknowledgments}

This research was supported by Cowtown Cruisin' for a Cure $^{\mathrm{TM}}$ and seed funding for interdisciplinary projects in the field of women's health focused on resources for health, education, and research from the University of North Texas Health Science Center. We thank Dr Zygmunt Gryczynski, for providing the spectrophotometer and fluorometer instrumentation and expertise for the AD-32 measurements. The atomic force microscopy studies were performed by Dr Irina Akapova.

\section{Disclosure}

The authors report no conflicts of interest in this work.

\section{References}

1. Caruthers SD, Wickline SA, Lanza GM. Nanotechnological applications in medicine. Curr Opin Biotechnol. 2007;18(1):26-30.

2. Jain KK. Applications of nanobiotechnology in clinical diagnostics. Clin Chem. 2007;53(11):2002-2009.

3. Davis ME, Chen Z, Shin DM. Nanoparticle therapeutics: an emerging treatment modality for cancer. Nat Rev Drug Discov. 2008;7(9):771-782.

4. Guo DD, Xu CX, Quan SJ, et al. Synergistic anti-tumor activity of paclitaxel-incorporated conjugated linoleic acid-coupled poloxamer thermosensitive hydrogel in vitro and in vivo. Biomaterials. 2009;30(27): $4777-4785$.

5. Freitas C, Müller RH. Correlation between long-term stability of solid lipid nanoparticles (SLN) and crystallinity of the lipid phase. Eur $J$ Pharm Biopharm. 1999;47(2):125-132.

6. Uner M, Yener G. Importance of solid lipid nanoparticles (SLN) in various administration routes and future perspectives. Int J Nanomedicine. 2007;2(3):289-300.

7. Yang SC, Lu LF, Cai Y, Zhu JB, Liang BW, Yang CZ. Body distribution in mice of intravenously injected camptothecin solid lipid nanoparticles and targeting effect on brain. J Control Release. 1999;59(3):299-307.

8. Hu LD, Tang X, Cui FD. Solid lipid nanoparticles (SLNs) to improve oral bioavailability of poorly soluble drugs. J Pharm Pharmacol. 2004;56(12):1527-1535.

9. Müller RH, Radtke M, Wissing SA. Nanostructured lipid matrices for improved microencapsulation of drugs. Int J Pharm. 2002;242(1-2):121-128. 
10. Lacko AG, Nair M, Paranjape S, Johnso S, McConathy WJ. High density lipoprotein complexes as delivery vehicles for anticancer drugs. Anticancer Res. 2002;22(4):2045-2049.

11. Lacko AG, Nair M, Paranjape S, Mooberry L, McConathy WJ. Trojan horse meets magic bullet to spawn a novel, highly effective drug delivery model. Chemotherapy. 2006;52(4):171-173.

12. Lacko AG, Nair M, Prokai L, McConathy WJ. Prospects and challenges of the development of lipoprotein-based formulations for anti-cancer drugs. Expert Opin Drug Delivery. 2007;4(6):665-675.

13. McConathy WJ, Nair M, Paranjape S, Mooberry L, Lacko AG. Evaluation of synthetic/reconstituted high density lipoproteins (rHDL) as delivery vehicles for paclitaxel. Anticancer Drugs. 2008;19(2):183-188.

14. Shahzad MM, Mangala L, Han H, et al. Targeted delivery of small interfering RNA using reconstituted high-density lipoprotein nanoparticles. Neoplasia. 2011;13(4):309-319.

15. Mooberry LK, Nair M, Paranjape S, McConathy WJ, Lacko AG. Receptor mediated uptake of paclitaxel from a synthetic high density lipoprotein nanocarrier. J Drug Target. 2010;18(1):53-58.

16. McConathy WJ, Paranjape S, Mooberry L, Buttreddy S, Nair M, LackoAG. Validation of the reconstituted high-density lipoprotein (rHDL) drug delivery platform using dilauryl fluorescein (DLF). Drug Deliv and Transl Res. 2011;1(2):113-120.

17. Vecchi A, Cairo M, Mantovani A, Sironi M, Spreafico F. Comparative antineoplastic activity of Adriamycin and N- trifluoroacetyladriamycin14-valerate. Cancer Treat Rep. 1978;62(1):111-117.

18. Israel M, Modest EJ, Frei E III. N-trifluoroacetyl adriamycin-14valerate, an analog with greater experimental antitumor activity and less toxicity than adriamycin. Cancer Res. 1975;35(5):1365-1368.

19. Krishan A, Israel M, Modest EJ, et al. Differences in cellular uptake and cytofluorescence of Adriamycin and $N$-trifluoroacetyladriamycin14-valerate. Cancer Res. 1976;36(6):2108-2109.

20. Wilkinson PM, Israel M, Pegg WJ, Frei E 3rd. Comparative hepatobiliary metabolism and excretion of adriamycin (ADR) and N-trifluoroacetyladriamycin-14-valerate (AD82) in the rat. Cancer Res 1978;38(2):365-370.

21. Witjes JA. Current recommendations for the management of bladder cancer drug therapy. Drugs. 1997;53(3):404-414.

22. Onrust SV, Lamb HM. Valrubicin. Drugs Aging. 1999;15(1):69-75.

23. Andersen SM, Rosada C, Dagnaes-Hansen F, et al. Topical application of valrubicin has a beneficial effect on developing skin tumors. Carcinogenesis. 2010;31(8):1483-1490.
24. Rosada C, Stenderup K, de Darkó E, Dagnaes-Hansen F, Kamp S, Dam TN. Valrubicin in a topical formulation treats psoriasis in a xenograft transplantation model. J Invest Dermatology. 2010; 130(2):455-463.

25. Ryan RO, Forte TM, Oda MN. Optimized bacterial expression of human apolipoprotein A-I. Protein Expr Purif. 2003;27(1):98-103.

26. Loney WW, Kudchodkar BJ, Weiss S, Clearfield MB, Shores J, Lacko AG. Evaluation of gemfibrozil therapy: predictive response from lipoprotein sub fraction analysis. Am J Ther. 1997;4(9-10):301-309.

27. Forte T, Norum KR, Glomset JA, Nicholas AV. Plasma lipoproteins in familial lecithin: cholesterol acetyltransferase deficiency: structure of low and high density lipoproteins as revealed by electron microscopy. J Clin Invest. 1971;50(5):1141-1148.

28. Kaighn ME, Narayan KS, Ohnuki Y, Lechner JF, Jones LW. Establishment and characterization of a human prostatic carcinoma cell line (PC-3). Invest Urol. 1979;17(1):16-23.

29. Fogh J, Fogh JM, Orfeo T. One hundred and twenty-seven cultured human tumor cell lines producing tumors in nude mice. J Natl Cancer Inst. 1977;59(1):221-226.

30. Murakami T, Wijagkanalan W, Hashida M, Tsuchida K. Intracellular drug delivery by genetically engineered high-density lipoprotein nanoparticles. Nanomedicine (Lond). 2010;5(6):867-879.

31. Venier-Julienne MC, Mathieu D, Filmon R, Phan-Tan-Luu R, Benoit JP. Development of 5-iodo-2'-deoxyuridine milling process to reduce initial burst release from PLGA microparticles. Int J Pharm. 1999;178(2):257-268

32. Leo E, Cameroni R, Forni F. Dynamic dialysis for the drug release evaluation from doxorubicin-gelatin nanoparticle conjugates. Int $J$ Pharm. 1999;180(1):23-30.

33. Yang CR, Zhao XL, Hu HY, et al. Preparation, Optimization and Characteristic of Huperzine A Loaded Nanostructured Lipid Carriers. Chem Pharm Bull (Tokyo). 2010;58(5):656-661.

34. Greenberg R, Bahnson R, Wood D, et al. Initial report on intravesical administration of $\mathrm{N}$-trifluoroacetyladriamycin-14-valerate (AD 32) to patients with refractory superficial transitional cell carcinoma of the urinary bladder. Urology. 1997;49(3):471-475.

35. Zheng J, Lee H, Bin Sattar M, Huang Y, Bian J. Cardioprotective effects of epigallocatechin-3-gallate against doxorubicin-induced cardiomyocyte injury. Eur J Pharmacol. 2011;652(1-3):82-88.

36. Ibsen S, Zahavy E, Wrasdilo W, Berns M, Chan M, Esener S. A novel doxorubicin prodrug with controllable photolysis activation for cancer chemotherapy. Pharm Res. 2010;27(9):1848-1860.
International Journal of Nanomedicine

\section{Publish your work in this journal}

The International Journal of Nanomedicine is an international, peerreviewed journal focusing on the application of nanotechnology in diagnostics, therapeutics, and drug delivery systems throughout the biomedical field. This journal is indexed on PubMed Central,

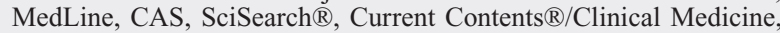

\section{Dovepress}

Journal Citation Reports/Science Edition, EMBase, Scopus and the Elsevier Bibliographic databases. The manuscript management system is completely online and includes a very quick and fair peer-review system, which is all easy to use. Visit http://www.dovepress.com/ testimonials.php to read real quotes from published authors. 